REVISTA DE DERECHO UNED, NÚM. 17, 2015

\title{
LA GESTIÓN DE LOS PROCESOS DE LA IRREGULARIDAD ESTRUCTURAL Y SOBREVENIDA EN ESPAÑA. ANÁLISIS MAQUETADO DEL ARRAIGO
}

\author{
THE MANAGEMENT OF THE PROCESSES OF THE \\ IRREGULARITY STRUCTURAL AND STRUCK IN SPAIN. \\ ANALYSIS LAYOUT OF THE ROOTING
}

\section{José Manuel Cerezo Mariscal ${ }^{1}$}

Resumen: El artículo se centra en la figura del acceso «estable» por el que discurre la inmigración irregular, hacia canales de legalización ordinaria. La praxis del arraigo como hecho social y como herramienta de regulación jurídica.

Abstract: The article focuses on the figure of the «stable» access along which illegal immigration toward legalization ordinary channels. The practice of roots as a social fact and as a tool of legal regulation.

Palabras clave: Migración irregular; arraigo y co-inclusión social.

Keywords: Migración irregular words; and co-rooted social inclusion.

Recepción original: 6/10/2015

Aceptación original: 28/10/2015

Sumario: I. Introducción: Sobre la política migratoria del arraigo. II. De lo intercultural a la co-inclusión: Conceptos y elementos que interpretan el paradigma migratorio. III. La inmigración regulada en España: una mirada sociojurídica. IV. La diáspora bajo auspi-

\footnotetext{
${ }^{1}$ Licenciado en Ciencias del Trabajo. Alumno en el Programa de Doctorado en Derecho y Ciencias Sociales de la UNED. Equipo de Investigación 4. Línea de Investigación I. Seguridad y Extranjería
} 
cios disformes. V. El no derecho que se hace derecho. VI. Los mecanismos de retroalimentación del arraigo: la irregularidad estructural y la irregularidad sobrevenida. VII. Conclusiones. VIII. Discusión. IX. Referencias.

\section{INTRODUCCIÓN: LA POLÍTICA MIGRATORIA DEL ARRAIGO}

Los procesos migratorios, caracterizados en nuestra sociedad actual por la recepción de volúmenes muy significativos de población extranjera comunitaria y no comunitaria, ha generado en los poderes públicos y también en la ciudadanía no pocas controversias. Así, en el ámbito de los estudios e informes, a contar por centenares, sino miles, en materias sociales y culturales de primer orden el fenómeno/conflicto se identifica con una palabra muy estigmatizada: «inmigración» y a esa acepción le añadimos el adjetivo «extranjera».

Las migraciones no son hechos «buenos» o «malos», no constituyen un reflejo estático de nuestros intereses individuales o colectivos y no deben construirse como fuente de conflicto, aunque la escasez provea de elementos conflictivos favoritistas y exogrupales. Las migraciones forman parte de nuestra naturaleza social y son consustanciales grafos humanos que discurren sobre espacios fronterizos artificiales, con vallas y campos minados que pretenden explosionar relaciones intergrupales categorizadas por el paso irregular de ilusiones deficitarias de comprensiones e ilustraciones racionalistas. Esta concepción metafórica del hecho migratorio, comparte espacios con otra visión holista de la sociedad que también interactúa con posiciones muy cercanas a la intercuturalidad, caracterizadas por un sincero progreso y esfuerzo en entenderse. Se propaga por grupos e individuos dispuestos a interactuar, contactar, dialogar y fomentar síntesis culturales y enriquecimientos mutuos.

Precisamente necesitamos centrarnos en determinadas situaciones hipotético-descriptivas, que al interaccionar con determinados instrumentos de control de los flujos migratorios, pensamos que pudieran haber favorecido la presencia continua de personas que no han podido obtener la documentación preceptiva que les avala la posibilidad de permanecer en España en situación legal.

Por eso compartimos la incertidumbre que pone de manifiesto el análisis del paradigma de la inmigración, bajo su condición de «no autorizada». La persona que no está autorizada a permanecer en un 
país, viene a cosificarse con la palabra «irregular», bajo el seudónimo de «inmigrante», sin entrar más allá en el uso nefasto que desemboca en la manipulación de un lenguaje muy estigmatizador. Pero en los Estados modernos la libertad de circulación de capitales y las tecnologías de la información y la comunicación, se contradicen con la libertad de circulación de personas, más sometidas a controles de tráfico que la política migratoria, proclive en el establecimiento de estrategias defensivas, tratan de postularse bajo el planteamiento de derechos que ponen en la balanza, los principios generales sobre los que se inspiran y la dignidad de la persona y sus derechos inherentes.

El trabajo prospectivo se centra en la figura del acceso estable que permite aflorar la inmigración irregular, hacia canales de legalización ordinaria; nos referimos a la autorización de residencia temporal por circunstancias excepcionales. Una gestada solución de la política migratoria, que se ha tildado con el vocablo denominado arraigo.

El arraigo se ha consolidado desde 2005, como el corolario que apoya la necesidad de contar con una salida a la inmigración irregular tanto la estructural, como la sobrevenida. -Y a esta solución española muy exclusiva en la Unión Europea, sostenida por una necesidad positivista de cara al afloramiento de este tipo de inmigración «no deseada», también pudiera ejercer de catalizador de la integración social-.

Pergeñar las políticas de integración, sobre la base del arraigo, como apéndice jurídico de la irregularidad migratoria, pudiera chocar frontalmente con la recesión económica que venimos padeciendo y su carencia o disminución, producto de la disminución de la demanda interna, podría resultar una fórmula proporcional a los flujos de entrada y retornos que se vienen produciendo.

Pero ¿por qué la política migratoria española se ha apoyado de manera pertinaz en el arraigo, a lo largo de estos casi diez años que comprenden su vigencia (etapa 2005 a 2015) ${ }^{2}$ como figura catalizadora de soluciones controvertidas? Trataremos de encontrar respuestas plausibles.

${ }^{2}$ La autorización de residencia temporal por arraigo, tal y como se regula hoy día, comenzó teóricamente a partir del 7 de febrero de 2005, fecha de la entrada en vigor del Real Decreto 2393/2004, de 30 de diciembre, si bien no dio sus primeros pasos hasta que no finalizó el proceso extraordinario de normalización que duró entre el 7-02-2005 y el 7-05-2005. 


\section{DE LO INTERCULTURAL A LA CO-INCLUSIÓN: CONCEPTOS Y ELEMENTOS QUE INTERPRETAN EL PARADIGMA MIGRATORIO}

Para poder construir un análisis descriptivo e interpretativo que permita dar cuenta de los efectos sociales relacionados con nuestro estudio, tendremos que incidir en un marco teórico que nos ayude a comprender nuestro modelo actual de sociedad, pues la ciencia es parca en descripciones y rigurosa en conceptos, por lo que es preciso asimilar los términos fundamentales que contribuyen a construir el multiculturalismo.

El hecho inmigratorio se relaciona con nuestro modelo de sociedad. Resulta palpable la realidad social cargada de prejuicios, de fórmulas sociales estereotipadas, del "novedismo ${ }^{3}$ insultante que interpreta al multiculturalismo incluso muy lejos de un concepto acorde con directrices éticas y equitativamente ligadas al concepto de bien común.

Por consiguiente, los ideales pragmáticos coexisten con posiciones bien lejanas de la proyección intercultural, sosteniendo otro enfoque crítico basado en la estricta idea de que la inmigración pudiera incluso ser perjudicial por múltiples factores (xenófobos, etnocéntricos, racistas, estigmatizados, de empleo sumergido e informal, de baja autoestima,.....de prejuicios y estereotipos).

Se interpretan las divisiones ideológicas surgidas de la industrialización del siglo XIX que, en palabras de Dassettto «se manifiestan en las formaciones políticas de izquierdas, de derechas y de centro; de comunistas y no comunistas...tienden a reducirse relativamente» (Dassetto, 2004: 101) replanteando formas colectivas que se posicionan socialmente y se identifican bajo otras formas colectivas mutadas. Dassetto nos sirve de referencia para interpretar el pluralismo que se influencia sobre la complejidad semántica contenida en el concepto de multiculturalismo y a las localizaciones y regulaciones sociales diferentes en las que el pluralismo emerge (Dassetto, 2004: 102).

De las concepciones basadas en el «triángulo multicultural» de Baumann que se apoya en la relación interactiva que existe entre cada uno de los factores principales -Estado-nación; Estado-Etnia; EstadoReligión y sus posibles formas combinables desde el punto de vista sociológico plantean la visión actual sobre la multiculturalidad ${ }^{4}$ (Bau-

\footnotetext{
${ }^{3} \mathrm{La}$ «manía» de ser originales y nuevos a cualquier precio, cueste lo que cueste.

${ }^{4}$ Conceptualizable como una realidad social compleja caracterizada por la diversidad cultural y la búsqueda del equilibrio de la sociedad puede relacionarse con la identidad multicultural.
} 
mann, 2001); discurriendo sobre la interpretación de la sociedad pluralista y multicultural de Sartori donde nos describe a una sociedad multigrupos es pluralista si, y solo si, los grupos en cuestión no son grupos tradicionales $\mathrm{y}, .$. , solo si se desarrollan «naturalmente» sin ser impuestos de alguna manera (Sartori, 2003: 39), nos postulamos en el análisis de Dassetto sobre los retos de la interculturalidad y su concepto sobre la «co-inclusión» (Dassetto, 2004: 104).

Nuestra sociedad, bajo el principio de territorialidad, necesita estar amparada en un sistema en el que el aseguramiento de la población (prevención, seguridad y económia) se identifican con los axiomas de funcionamiento de la sociedad. La vida cotidiana y sus relaciones sociales y políticas; las instituciones de autogobierno con bases democráticas y el mercado laboral y sus distintas concepciones, establecen una notoria influencia sobre los elementos grupales que se vienen redefiniendo por las fluctuaciones que discurren sobre procesos. Procesos que para nuestro análisis, entre inmigrantes y autóctonos, los dividimos en visibles e invisibles, caracterizados los primeros por acceder formalmente a la sociedad de acogida, mediante relaciones sociales aceptadas por ambas partes, pero lejos de la igualdad que debe acogerse al estatuto político.

Los invisibles se caracterizan por los elementos que De Lucas (2011: 4) describe y los caracteriza por la invisibilidad política; la invisibilidad de un estatus de sumisión y el compromiso que se basa en la concepción de Hobbes sobre el súbdito político, aunque la política migratoria (de la Unión Europea y, por ende, de España) se tiene que construir desde la alteridad, donde la imagen del «otro» se contrapone al de «nosotros» y donde el derecho de la inmigración extranjera (término más acorde con el de derecho de extranjería, anticuado y procedimentalmente obsoleto), se sostiene sobre una regulación que se ha amparado en la degradación del trabajo, por el empleo y la del estatuto del trabajador asalariado, acogido en estratos laborales, donde las ocupaciones inferiores casi conforman los únicos nichos de empleo de la inmigración extranjera.

Pero esta diferenciación entre el la visibilidad e invisibilidad del «otro», también se torna sinónima con las pretensiones de homogeneidad propias del monismo ontológico y deontológico (De Lucas, 2014: 85) que se construyen como desiguales, con el resultado social que se confunde entre la acepción extranjero con la simbólica de inmigrante, porque los derechos humanos no son una realidad natural, un dato esencial metafísico, sino un producto, mejor, una conquista histórica (De Lucas, 2014: 86) diferenciada en una igualdad 
compleja que Honneth denominó la sociedad del menosprecio ${ }^{5}$ donde la coexistencia es un riesgo que se define en la relación entre "propios» y «extraños», bajo el paraguas de la aceptación o co-inclusión recíproca de Dassetto: «Hablar de co-inclusión no significa suprimir el conflicto, las tensiones, las oposiciones...pues co-inclusión supone igualmente la posibilidad de un cierto acuerdo de las partes en conflicto...un reconocimiento del otro...; un término que señala la reciprocidad del proceso...que requiere tiempo, investigaciones y ensayos-errores recíprocos, un auténtico trabajo para las sociedades» (Dassetto, 2004: 104).

Llegamos pues, a las diferencias y a los rechazos que partiendo de un lado, se tornan recíprocos, necesitando acudir al elemento de la regulación para la controlar los flujos y acudiendo con ello a las capacidades de los estados supra-nacionales para dar respuesta a la entrada masiva de personas de diferentes etnias añadiendo el objetivo de controlar (más si cabe, diríamos, identificar) las expresiones radicales centradas en el fracaso que, desembocando en conflictos dentro de los procesos de civilización, confluyen poblaciones abanderadas por sus culturas, más allá de los apodados «ciclos migratorios» pues las migraciones son tan antiguas como la propia civilización humana.

$\mathrm{Y}$ los procesos migratorios incluyen movimientos que en muchos casos se sostienen por debajo del umbral de la regulación legal, tal que la precariedad en los recovecos de la ley promueve la irregularidad de los flujos migratorios, puesto que lo que no se alcanza por los mecanismos legales amparados por el Derecho de la inmigración se yergue por el hecho en sí. Inmigración clandestina, irregulares, infrasujetos, presencia ausente ${ }^{6}$, se enfrentan al reconocimiento social a través de vericuetos jurídicos que la denominada Ley de Extranjería ${ }^{7}$ ha pretendido solucionar. Los términos intercultural, diverso, pluralismo cultural, procesos, ciclo migratorio, co-inclusión societal, ante el reto de los investigadores a destruir la cismogénesis de Bateson ${ }^{8}$

${ }^{5}$ (DE LUCAS, 2014:87)

${ }^{6}$ Habitualmente se suele identificar al sujeto con el adjetivo, con lo cual, se discrimina a la persona en vez de tratar de reflejar únicamente su situación de permanencia legal, irregular o ilegal en España.

${ }^{7}$ Por Ley de Extranjería, entendemos a la regulación de la inmigración extranjera operada en España mediante la Ley Orgánica 4/2000, de 11 de enero de los Derechos y Libertades de los Extranjeros en España y su Integración Social.

${ }^{8}$ Citado por DASSETTO (2004:104) para conformar su planteamiento sobre la coinclusión y los procesos que pudieran coadyuvar a conceptualizarla desde esa perspectiva muy compleja, pero aceptable si la comparamos con los descriptos del «ciclo migratorio» y la «integración», puesto que la indisposición a un acuerdo en un conflicto entre los autóctonos y los «otros» desembocan en rechazos unilaterales y recíprocos alejándose con ello de las relaciones en suma positiva entre las poblaciones. 
contribuyendo con ello a comprender, descifrar e identificar los códigos culturales que comprenden nuestra sociedad actual, se enfrentan al conocimiento de la realidad social, tratando de dar respuestas más allá de los conocimientos específicos y contingentes.

Y henos aquí que parece que estamos como al principio, barajando definiciones y conceptos, pero la regulación de la inmigración es una respuesta manipulada para diferenciar lo que queremos de lo que tenemos. Interpretamos la regulación de la inmigración, construyendo normas de exigencia obligatoria, que se diluyen en procesos de regulación (ordinarios y extraordinarios) pero la relación causa-efecto, necesita de una investigación que permita identificar la explicación causal de los fenómenos en general y de la persistente irregularidad migratoria en particular.

\section{LA INMIGRACIÓN REGULADA EN ESPAÑA: UNA MIRADA SOCIOJURÍDICA}

Los procesos desde la visión de las migraciones, argumentados por Dassetto, nos llevan a comprender que los hechos migratorios son consustanciales a los tiempos -cronológicos y sociales- en que se producen, como si estuviéramos siendo actores de las revoluciones culturales que comportan, pero mutando aleatoriamente en relación al bienestar social que subjetivamente perciben los que desean asentarse en otras tierras distintas a las que vieron nacer y la percepción de los autóctonos en tanto que se sienten más o menos amenazados en la convivencia.

La suma de procesos (de decisión de emigrar; de entrar en territorio de otros países supuestamente más favorables de acogida; de búsqueda de supervivencia en el territorio de acogida; de permanencia temporal o de larga duración...etc.) permiten los asentamientos poblacionales multiétnicos. Son procesos dinámicos que pueden o no estar compelidos por reglas; por normas de regulación y convivencia; que pudieran entroncar con la co-inclusión, pues la integración nos parece más bien un término más estático, más proclive a la regulación legal impuesta (de mayor o menor componente ideológico en cuanto a la gestión de los servicios sociales básicos) frente al menor o mayor grado de reconocimiento social de la persona que llega a otras tierras. Ese escalado grado de reconocimiento es recíproco entre las partes interesadas, con lo cual, esa graduación, cuando se radicaliza y se inclina al extremo de la escala social, nos podemos topar con las rémoras racistas y xenófobas. 
Para nuestro análisis nos centraremos en los procesos de entrada en territorio español -territorio de la Unión Europea-; los que conforman el asentamiento, sea temporal o de larga duración. Y dentro de esta división, el cumplimiento de las normas jurídicas que comportan la entrada, permanencia y salida están muy correlacionadas con los procesos de asentamientos irregulares, pudiendo ser éstos -a su vezdiferenciados en asentamientos irregulares estructurales y asentamientos irregulares sobrevenidos, que vamos a conceptuar para mayor identificación de las tendencias prácticas que los constituyen tendiendo a la co-inclusión recíproca, pues como venimos argumentando, la co-inclusión -al igual que la integración- es un término que forma parte del paradigma inmigratorio, de origen comportamental que plantea múltiples interrogantes.

El andamiaje de la irregularidad, se soporta bajo elementos exo y endrogrupales apoyados por formas estereotipadas de convivencia que peregrinan desde sus países de origen o asentamientos más permanentes, hacia países más desarrollados. Es la nueva conformación de la inmigración que se basa en la transitoriedad permanente.

La cesión de soberanía conlleva la puesta en funcionamiento del espacio de libertad, seguridad y justicia ya plasmado en el Tratado de Funcionamiento de la Unión Europea (TFUE) ${ }^{9}$. Goig Martínez aprecia un importante avance en la gestión y el control de los flujos migratorios, pero una desajustada y poco equitativa balanza hacia el trato de los inmigrantes, con el resultado de una "política restrictiva en cuanto a entrada y permanencia de extranjeros de terceros países que también se ha visto reflejada, y en algunos casos impulsada por ella misma, en el ámbito de derechos y libertades para inmigrantes» (Goig, 2008: 32). Estos son los hechos ${ }^{10}$.

En esta síntesis explicativa, las migraciones irregulares se documentan para poder realizar entradas y permanencias fuera de los requisitos legales que conforman la estancia y la permanencia en la Unión Europea. España, al igual que Italia, constituyen la frontera Sur de los Estados Miembros y los dos países que gestionan un alto porcentaje de la inmigración clandestina que trata de traspasar las fronteras exteriores.

Y para poder obtener autorización de residencia en nuestro país, será necesario cumplir los requisitos que se han establecido a través

${ }^{9}$ Artículo 67 del Tratado de Funcionamiento de la Unión Europea (TFUE).

${ }^{10}$ Los intentos por franquear las fronteras europeas de Ceuta y Melilla, son un claro ejemplo de las necesidades que se entroncan con esas vallas, creando un conflicto frontal con el espacio de libertad, seguridad y justicia de la UE. 
del Derecho Social de la Inmigración ${ }^{11}$, un cuerpo jurídico incipiente que entronca con el principio de co-inclusión, lo que significa identificar los conceptos que conllevan a que los procesos de la inmigración nos permitan componer esos receptores-transmisores que racionalizan la aceptación compartida entre presentes -sean o no de otras nacionalidades-. Las redes organizadas pueden proceder desde los países de origen, pasando por los países sobre los que discurren las personas, llegando a destino temporal en Europa y asentándose también con ayuda. Las redes son formales o informales, pues esa promoción desde componentes de voluntariedad en la decisión de inmigrar, hasta la ausencia de voluntad que comportaría o desembocaría, más bien, en la trata de seres humanos. Y en todo este complejo en plena diáspora migratoria, se encuentran las situaciones humanitarias, tampoco exentas de ayuda ¿Cómo se interpretan los conceptos y las variables que conforman la permanencia irregular o ilegal? A continuación lo analizamos.

\section{LA DIÁSPORA BAJO AUSPICIOS DISFORMES}

No cabe duda en reconocer que las migraciones que nos resultan propicias, están bajo el paraguas del empleo, principalmente el cualificado y el resto de ocupaciones laborales. La ley encorseta al empleo «menos cualificado» o incluso, el «no cualificado» dentro de la estructura legal de residencia temporal e, incluso, de la residencia de larga duración. Este planteamiento está insertado en las normas de la Unión Europea y en las normas migratorias internas españolas.

Surge de esta manera el estereotipo de los infrasujetos que describe De Lucas (2014: 88) agrupándose bajo la batuta lingüística de «irregulares»; «ilegales»; «invisibles»; cuentan con derechos acotados constitucionalmente. Vamos a retroceder en el tiempo y la primera norma relacionada con el Derecho de Extranjería, la Ley Orgánica 7/1985, de 1 de julio ${ }^{12}$, forjaba bajo elementos claramente circuns-

${ }^{11}$ Podemos identificarlo como un cuerpo jurídico consistente no sólo en el denominado Derecho de Extranjería, sino también del conjunto de normas jurídicas que permiten establecer la conexión entre el mero cumplimiento legal de entrar, permanecer y salir, sino también de adherirse al cumplimiento de las normas que conforman los derechos sociales básicos, ponderando desde la interpretación legal la integración de la inmigración en España.

${ }^{12}$ Esa Ley Orgánica se denominaba «sobre derechos y libertades de los extranjeros en España», cuando en realidad estaba sesgada por el derecho administrativo de frontera. Se publicó en el BOE de 3 de julio de 1985 y estuvo vigente hasta el 1 de febrero de 2000, con la entrada en vigor de la Ley Orgánica 4/2000, de 11 de enero.

(C) UNED. Revista de Derecho UNED, núm. 17, 2015 
pectos y lejanos a la co-inclusión, discriminando notoriamente a los aceptados denominados extranjeros en situación legal de los que se encontraban en situación de ilegalidad. La Exposición de Motivos nos ilustra sobre esos elementos constructivos del concepto en relación a la situación administrativa de permanencia en España

Así, constituye ejemplo para confundir los términos, la Exposición de Motivos de esta primera norma con rango de Ley, que se contradecía terminológicamente con la Disposición Transitoria Segunda del mismo precepto, alejándose de esa intención de diferenciar a los nacionales de otros países, con o sin permanencia legal en nuestro país pues establecía la posibilidad de otorgar autorizaciones de residencia a inmigrantes extranjeros que se encontraran en España insuficientemente documentados, con lo cual, ya se amenazaba la concreción del concepto y se derivaba en una nueva línea argumental que hoy día ya conocemos como «permanencia irregular»; «extranjeros que se encuentran en situación irregular».

Y como exponemos, la Ley Orgánica 7/1985 referencia de partida, desde la visión historicista ${ }^{13}$, en su artículo 11 , instrumentaba a las personas cuya presencia en nuestro país no revestía de los requisitos para obtener una autorización de residencia legal, diciendo que

«Se considerará ilegal a toda forma de entrada en el territorio nacional en la que no concurran las circunstancias descritas...», para más adelante, en su artículo 12, posibilitar aún más, la intención definitoria al sostener que «Solo se considera extranjeros residentes las personas amparadas en un permiso de residencia.»

En consonancia con la citada Ley Orgánica, el Real Decreto $1119 / 1986$, entre otros preceptos, en su artículo 75 , se refería como sujeto infractor, a los que se encuentren ilegalmente...; y posteriormente, el Real Decreto 155/1996, en su artículo 98, igualmente realiza una labor continuadora de la acepción para tipificar al sujeto infractor que se encuentre ilegalmente en territorio español...

Es a partir de la Ley Orgánica 4/2000, cuando se viene a reconocer que se estaba gestando un concepto alejado de los actos de las personas, en relación con la permanencia en un espacio de territorio. Pero lo cierto es que las personas realizarían actos administrativos lícitos o ilícitos, que serán reprobables según cumplan o no con los mínimos requisitos para ser aceptados por la comunidad que los acoge. Así, la visión de la permanencia ilegal es sustituida por la permanencia irre-

${ }^{13}$ Corriente de pensamiento que sostiene que la naturaleza de las personas y de sus actos solo es comprensible si se los considera como parte integrante de un proceso histórico. http://es.thefreedictionary.com/historicismo 
gular, dando cumplimiento a las conclusiones adoptadas en el Consejo de Tampere en octubre de 1993 y donde espacio de libertad, seguridad y justicia se corresponde con la libertad de circulación, limitándose el espíritu de los legisladores y aceptando la irregularidad migratoria como un efecto secundario de los cambios conceptuales legales aprobados por las instituciones de la Unión Europea. Pero las migraciones irregulares tienen su lugar respecto de la aceptación por parte de la comunidad que los percibe y visualiza. Y los hechos postulan respuestas jurídicas cuando se generalizan y son visibles.

Por ello, el primer Reglamento de desarrollo de la Ley Orgánica 4/2000 -el Real Decreto 864/2001- vino a establecer una advertencia no desdeñable, en la regulación de la declaración de entrada de un migrante a España -el artículo 29 de dicho texto- recoge explícitamente la obligación de realizar ese acto administrativo ante las autoridades policiales españolas, para, en su segundo párrafo matizar las consecuencias: «Si no acreditan los requisitos previstos en la normativa vigente, su permanencia en España será irregular». De modo que desaparece la ilegalidad en la ley y en el reglamento de desarrollo, para ir asentando el término irregular en todas las alusiones relacionadas con la inmigración irregular -la Exposición de Motivos del Real Decreto 2393/2004, ya matiza una vieja aspiración al «priorizar la inmigración legal... para perseguir más eficazmente la inmigración irregular» y llegamos hasta la norma actual, el Real Decreto 557/2011, que viene a realizar en ese sentido una línea continuista en torno a la permanencia irregular.

Pero ¿cómo interpreta la Jurisprudencia el término?

En línea argumental, el Tribunal Constitucional, en su Sentencia 95/2003, de 22 de mayo, -Fundamento Jurídico 1. ${ }^{\circ}-$, también hace alusión a los extranjeros que se encuentren ilegalmente en territorio español, pero, al mismo tiempo, en la abstracción instrumental interpretativa, en su fundamento Jurídico $7 .^{\circ}$ realiza esta sorprendente aclaración: «..que residan legalmente habrá de entenderse referida a una situación puramente fáctica de los que se hallan en territorio español, sin que quepa atribuir un significado técnicamente acuñado de residencia autorizada administrativamente...». Y el Tribunal Supremo mediante Sentencia 92/2014 (Recurso de Casación 407/2013) en su Fundamento Jurídico 5. ${ }^{\circ}$ determina «sancionar la entrada ilegal».

Es decir, que el problema de la indefinición conceptual desde la perspectiva jurídica y desde el análisis social, destila a lo largo del tiempo la acuñación de términos bajo el enigma de la incertidumbre propiciando inseguridad; la utilización de un lenguaje estereotipado 
y desdotado de reglas comunes que han desembocado en planteamientos xenófobos y la falta de un sentido político-jurídico a los términos empleados, con divagaciones amparadas en un bagaje politicamente desautorizado apoyado por una política migratoria que parece divagar sin rumbo.

Y del devenir del migrante irregular como "persona que carece de condición legal en un país anfitrión o de tránsito» (CIPDH, 2010) nos vamos entrando en la figura del migrante irregular como sujeto final y más vulnerable del peso de la ley, que dificulta el diseño de la investigación por falta de conceptos dotados de variables y que confluyan en expectativas más centradas en el hecho y sus repercusiones. En el glosario de términos de la Unión Europea, se tiende a establecer una similitud respecto de la situación de entrada (ilegal/irregular) y de permanencia (irregular/ilegal) en aras de admitir que, en uno u otro caso, se está vulnerando el derecho de los Estados Miembros a proteger sus fronteras y regular jurídicamente la libertad de asentamiento bajo la legalidad.

En España la salida legal y natural de la permanencia irregular/ ilegal se encorseta bajo la regulación permanente, tratando de desprenderse de las criticadas regulaciones extraordinarias o procesos extraordinarios de regulación, dada su repercusión jurídica y social. La regulación permanente está considerada por la Ley como una autorización de residencia extraordinaria y ésta cualitativa y cuantitativamente discurre sobre la figura del arraigo, punto de inflexión de este análisis.

\section{EL NO DERECHO QUE SE HACE DERECHO}

Pero para acercarnos a la descripción de la regulación permanente, nos proponemos afirmar que en toda investigación, por parca que se precie, necesita estar acogida a los principios de rigor, objetividad, y grandes dosis de observación y aunque los elementos definitorios plantean dudas respecto la posición de quién trata de establecer proposiciones relacionadas, (irregularidad, ilegalidad, clandestinidad... como ejes que vienen a identificar la ausencia de conceptos aceptados científicamente), debemos tratar de segmentar los hechos empíricos regulares, para poder inferir predicciones empíricas. (Corbetta, 2007: 71).

Tratar de reconocer y explicitar la persistencia de la inmigración irregular en España es un reto que contiene múltiples proposiciones teóricas: véanse la inmigración multidimensional (Izquierdo y León- 
Alfonso, 2007); los construidos como desiguales (De Lucas, 2014); la inviabilidad de la inmigración cero (Arango, 2005) deparando el enfoque global comunitario (Llíes, 2009). Proposiciones que entroncan con hipótesis explicativas sobre las que puedan sostenerse pruebas empíricas para poder formular, posteriormente resultados. Proposiciones que entroncan con hipótesis explicativas sobre las que puedan sostenerse pruebas empíricas para poder formular, posteriormente resultados. Y en esta fase analítica debemos sintetizar los principales puntos de abstracción que identifican el componente de la entrada y permanencia irregulares:

a) Entrada legal, con visado de estancia por tiempo determinado y no regreso al país de origen.

b) Entrada sin documentación apta para estancia o residencia.

c) Denegación de asilo.

d) Pérdida de la permanencia legal, por caducidad o por extinción diversa de la autorización de residencia legal (extinción por vía administrativa o por vía judicial).

e) Salida obligatoria no ejecutable; retorno no ejecutable, ambos supuestos, bien por vía administrativa o por vía judicial.

Estos cinco puntos esenciales pueden constituir el hecho explicativo ad hoc de la irregularidad en la forma de entrar y en la forma de permanecer, aunque la salida no voluntaria que no se haya podido llevar a efecto por múltiples causas, entre las que la ley ejerce de mecanismo inductor de esa negación, bien por haberlo así acordado el legislador o por vía interpretativa desde la visión jurisdiccional de los hechos concretos.

Ahí está una de las cuestiones principales: que la ley se tiene que abstraer a la concreción más que a la generalidad. Estos elementos o sesgos que identifican desde la Sociología o desde el Derecho a las personas que tratan de asentarse sin contar con la autorización de un Estado, en este caso, en España, los relacionaremos con la hipótesis de que la regulación permanente en nuestro país, que se denomina arraigo viene a constituir el catalizador principal de la promoción y asentamientos irregulares temporales de migrantes. Hablamos de generalidad, descontando a los que migran por conflictos bélicos, persecuciones, solicitantes de asilo y refugio.

Así, mientras que el núcleo principal de las regularizaciones masivas extraordinarias, posiblemente venían sostenidas por las distintas modificaciones en la gestión de la política migratoria en España, el 
arraigo se viene a construir, en principio como un medio naturalizado más integrador, para a lo largo del tiempo, haberse constituido en un error sistemático apoyado por factores exógenos y endógenos que la propia gestión migratoria ha propiciado, de momento sin posibilidad de cambio.

Analicemos la unidad a estudiar: el arraigo como factor concatenante de expectativas sobre las que se construyen la irregularidad en la entrada y permanencia, amparada por los requisitos que la ley gestiona a través de su reglamento de desarrollo y de las instrucciones y circulares administrativas de los Ministerios implicados.

\section{V.1 Aproximación maquetada al arraigo}

El arraigo, desde esta visión de las migraciones, podemos entenderlo como el proceso abierto y reversible por el que una persona no nacional de un concreto Estado ha superado sus fronteras y prolonga su permanencia en el territorio de dicho Estado un tiempo determinado, bajo intereses, lazos o vínculos familiares, económicos y sociales que permiten justificar su presencia en España ${ }^{14}$. Y nos acogemos a los elementos más generalistas que, con ayuda de la Jurisprudencia y la labor hermenéutica ${ }^{15}$ de los Tribunales Superiores de Justicia:

- La permanencia en España se viene a justificar por intereses, lazos o vínculos familiares, económicos y sociales para un caso concreto.

- El hecho de seguir estudios con suficiente asiduidad y aprovechamiento.

— La reagrupación y la integración familiar.

- El disfrute de autorización de trabajo o el haber sido previamente titular de autorización de residencia.

— Que la persona debe apreciar el interés en residir en España.

${ }^{14}$ Sobre los criterios que permiten identificar el arraigo, nos basamos en la jurisprudencia del Tribunal Supremo y de la labor hermenéutica de los Tribunales Superiores de Justicia. Así, la STS 24-XI-2014 (Recurso 6922/2002); de 11-IV-2000; 14-III2002; 16-VII-2002 y Sentencia del Tribunal Superior de Justicia de Castilla-La Mancha de 2-III-2015 (Recurso 201/2013), entre otras.

${ }^{15}$ Según BEUCHOT (2008: 494) es la búsqueda o el sentido literal histórico, pero entendido como coherencia o consistencia completa. 
- El término arraigo tiene una interpretación extensiva, acogiéndonos al artículo 124 del Real Decreto 557/2011, de 20 de abril.

Pero el posicionamiento conceptual del arraigo desde la perspectiva jurídica, trata de reconocer a quiénes desean que esa situación se vea modificada para poder conseguir una residencia legal y consecuentemente, buscar un sustento que le permita subvenir a sus necesidades.

Este es el argumento de partida del no derecho que se hace derecho.

Como venimos exponiendo, en España, el presupuesto de hecho que conceptualiza el arraigo, desde la Ley, se desarrolla con el Real Decreto 2393/2004, de 30 de diciembre, una vez finalizado el denominado Proceso de Normalización que regulaba la Disposición Adicional Tercera del citado Texto ${ }^{16}$. Es a partir de ese proceso cuando se trata de armonizar una serie de normas jurídicas que trataban de regular lo que denominamos integración gestionadas por las Administraciones del Estado, de las Comunidades Autónomas y de la Administración Local, con muy diversos resultados, lo que ha complicado el proceso de co-inclusión societal.

Los ocho países con mayor peso de solicitudes aprobadas en el Proceso de Normalización fueron:

— Ecuador con 127.925.

- Rumanía con 100.128.

- Marruecos con 68.727.

- Colombia con 50.417.

— Bolivia con 39.773 .

- Bulgaria con 22.239.

- Argentina con 21.519.

— Ucrania con 19.466.

${ }^{16}$ El Proceso de Normalización estuvo dividido en tres etapas: Desde 7-02-2005 hasta 7-05-2005 de recepción de documentación; desde 7-05-2005 hasta prácticamente el mes de noviembre de 2005, en función de los volúmenes de gestión a nivel provincial, podríamos considerar las fases de instrucción y resolución para, finalmente, a primeros de 2006, cuando comenzó en la práctica las fases de instrucción y terminación de los primeros expedientes de arraigo. 
Como puede comprobarse el perfil socioestructural del Proceso estaba sustentado por América Latina (Ecuador, Colombia, Bolivia y Argentina) que representaban el $41 \%$ del total de autorizaciones concedidas, seguidas de Rumanía y Bulgaria, cuyo valor relativo era del 21\%, para, finalmente como representante del continente africano, del Magreb, sea Marruecos el país que contaba con un 12\% del total de las 161 nacionalidades. Esta presencia ausente convertida en legalidad presente, declina las hipótesis de partida sobre la mayoría que podría comportar la Normalización, basada en nacionalidades procedentes del África Subsahariana y del Magreb. Una vez más, las previsiones se alejaban de la realidad en su apreciación, pero se construían soluciones plausibles tratando de dar respuesta a las entradas y permanencias masivas con una visión un tanto trastocada, como así recoge Lahlou (2006: 12)

«Le Maroc doit renforcer le contrôle de ses frontières et accroîte su coopération dans la lutte contre le trafic d'inmigrants clandestins ${ }^{17}$.»

Finalizado el Proceso de Normalización que regulaba la Disposición Adicional Tercera del Real Decreto 2393/2004'18, el arraigo comienza su andadura actual planteando con su puesta en escena la necesidad de armonizar una serie de normas jurídicas que trataban de regular lo que denominamos integración gestionadas por las Administraciones del Estado, de las Comunidades Autónomas y de la Administración Local, con muy diversos resultados, lo que ha complicado el proceso de co-inclusión societal.

El Proceso de Normalización planteó una expectativa positiva, si tenemos en cuenta el volumen de expedientes que permitieron aflorar la permanencia irregular hacia la obtención de la preciada autorización para residir y trabajar en España. Si recurrimos a los datos ${ }^{19}$, una vez finalizado el referido Proceso, se concedieron 578.375 autorizaciones de las 691.655 solicitadas, lo que representaba un peso del 83\%. Ahí quedaron 113.280 personas que habían solicitado la autorización para residir y trabajar, pero no la obtuvieron por no cumplir los requisitos establecidos. El resto de personas que permanecieron en situación irregular, bien por no cumplir los mínimos exigidos

${ }^{17}$ Marruecos debe reforzar el control de sus fronteras e incrementar su cooperación en la lucha contra el tráfico de inmigrantes clandestinos (la traducción es mía). Declaración de Jesús Caldera, ministro español de Trabajo a primeros de 2005.

${ }^{18}$ El Proceso de Normalización estuvo dividido en tres etapas: Desde 7-02-2005 hasta 7-05-2005 de recepción de documentación; desde 7-05-2005 hasta prácticamente el mes de noviembre de 2005, en función de los volúmenes de gestión a nivel provincial, podríamos considerar las fases de instrucción y resolución para, finalmente, a primeros de 2006, cuando comenzó en la práctica las fases de instrucción y terminación de los primeros expedientes de arraigo.

${ }^{19}$ Fuente: Secretaría General de Inmigración y Emigración y elaboración propia. 
por la regularización normativa, bien por otros elementos influyentes como la falta de obtención de la documentación necesaria o por no poder acreditar la presencia ausente administrativa e institucional, quedaron a merced y espera de la regulación que el arraigo prometía.

Pero a lo largo del tiempo se ha podido comprobar que las previsiones se alejaban de la realidad en su apreciación, pero se construían soluciones plausibles tratando de dar respuesta a las entradas y permanencias masivas con una visión un tanto trastocada.

\section{V.2 El arraigo español como causa propositiva y consecuencia del error sistemático y del error aleatorio en la gestión de la política migratoria española}

Con independencia de los sesgos que se identificaron en el Proceso de Normalización, el proceso extraordinario permanente sobre el que se asienta el arraigo desde el año 2006 -en sus tres formas gestionables-, venía avalado por una mejora en la transparencia en la gestión de los flujos y por los medios materiales y humanos que se han dispuesto en la gestión de las autorizaciones administrativas y, esa mejora se enfrentaba -y sigue enfrentándose- a los factores que distorsionan el acceso individual que transcurre desde la irregularidad hacia la legalidad: los requisitos o, mejor dicho, la apariencia de cumplimiento de los requisitos como se viene detectando.

Nos apoyaremos en datos facilitados por la Secretaría General de Inmigración y Emigración ${ }^{20}$-en adelante, SGIE- para postular una descripción del arraigo.

Entre el período que comprende 2006 a 2014, se han solicitado 747.685 autorizaciones de residencia por circunstancias excepcionales, por arraigo, que además, comporta autorización para trabajar. El artículo 124 del vigente Reglamento que desarrolla la Ley Orgánica 4/2000, de 11 de enero, plantea tres tipos de arraigo: laboral, sociolaboral (que denominaremos social, por su perspectiva integradora) y familiar.

Partimos del planteamiento legal de que este tipo de autorizaciones se ciñen a la temporalidad, por una parte, a la residencia, como segundo elemento, que comporta, como decimos, autorización para

${ }^{20}$ Los datos son facilitados por la Subdirección General de Inmigración y está adscrita a la Dirección General de Migraciones que se encuadra en la Secretaría General de Inmigración y Emigración del Ministerio de Empleo y Seguridad Social. 
trabajar en las tres variedades y a la excepcionalidad del tipo de autorización.

Pero en realidad se está palpando una solución a la irregularidad reiterativa entendida como un proceso que se retroalimenta en tanto en cuanto, si el inmigrante extranjero pierde por las causas legales, su residencia, algunos juzgados interpretan que no existe inconveniente en volver a solicitar la autorización por arraigo complicando aún más la situación de permanencia, puesto que a la acentuada crisis económica, con una altísima tasa de paro, no encajan las promesas de contrataciones de personas que se encuentran en permanencia irregular, quedando a merced de desaprensivas soluciones.

Y si ponemos en relación lo que analizamos, resulta de mayor complejidad dar aplicación práctica a la Directiva de 2008 que regula el procedimiento de retorno ${ }^{21}$ en la Unión Europea (y en España), que mantener en la irregularidad estructural a las personas que no pueden obtener o no pueden renovar las autorizaciones de residencia y trabajo temporales, pues en esa reiteración de autorizaciones extraordinarias -palabra fuera de contexto cuando lo extraordinario se torna en ordinario como venimos argumentando- la irregularidad sobrevenida se torna ya en los parámetros de la estructuralidad con el perjuicio que comporta desde la seguridad y la co-inclusión societal. Es decir, que el proceso legal se convierte en un círculo de transformaciones desde la irregularidad estructural, acceso a la residencia temporal, pérdida de la residencia temporal y partimos de cero con la irregularidad sobrevenida. Analizamos en el apartado siguiente este vericueto, puntualizando la situación actual.

\section{LOS MECANISMOS DE RETROALIMENTACIÓN DEL ARRAIGO: LA IRREGULARIDAD ESTRUCTURAL Y LA IRREGULARIDAD SOBREVENIDA}

El desarrollo del artículo 31.3 de la Ley Orgánica 4/2000, de 11 de enero, se sustenta sobre los tres tipos de arraigo: A) Laboral. B) Social o sociolaboral. c) Familiar. Analicemos sus diferencias y cercanías en lo social y en las cifras resumidas.

${ }^{21}$ La Directiva de retorno, como así se la conoce, regula la salida obligatoria y la salida forzosa, en caso de incumplimiento de dicha obligación, que también se conoce como expulsión, de los no nacionales de los Estados Miembros que no han obtenido solución a la permanencia irregular o bien, que han sido compelidos a dejar el territorio europeo por la comisión de ilícitos administrativos o delitos graves. 


\section{VI.1 El arraigo laboral}

Esta figura nacía con la pretensión de luchar contra la permanencia irregular de inmigrantes extranjeros y que compatibilizaban su situación ya de por sí precaria, con el trabajo y la sobreexplotación laboral. Pero en la realidad existe un fuerte condicionamiento social a la denuncia y en muchas ocasiones no prosperan. En cuanto al alcance del objetivo del legislador, cualitativamente respetable, cuantitativamente es apenas una reseña en un extenso texto.

Los requisitos para poder acceder a esta solución administrativa extraordinaria, están sostenidos por dos aspectos fundamentales: el primero, acreditar la permanencia irregular continuada en nuestro país de dos años y demostrar la existencia de relaciones laborales cuya duración no sea inferior a seis meses y se admiten como prueba de trabajar o haber realizado trabajos, una resolución judicial que reconozca la misma o bien, una resolución administrativa confirmatoria del acta de infracción de la Inspección de Trabajo y Seguridad Social.

Se traslada pues la posibilidad de obtener una autorización de residencia temporal por esta vía, a la necesaria acreditación de una relación laboral sin contar con una autorización administrativa previa, que está tipificada como infracción administrativa muy grave, siempre que el hecho no constituya delito, con lo cual, el empleador o empresario se enfrenta a la incertidumbre de hacer aflorar la posible comisión de un delito y si no prospera una sentencia condenatoria, entonces cuando menos se vería inmerso en un procedimiento administrativo sancionador con una multa de 10.001 euros como mínimo, aparte de las cotizaciones a la Seguridad Social y Desempleo -en su caso- que tendría que sufragar con recargos de mora o apremio e intereses de demora.

Entre 2006 y 2014, se solicitaron en España 12.406 autorizaciones de residencia temporal por este procedimiento, de las que 7.307 se concedieron. En términos relativos representa un 59\% de las solicitadas, pero a estos datos donde un $41 \%$ no obtuvieron resultado, peor aún resulta intrascendente si la cifra porcentual la comparamos con el total de autorizaciones de arraigo (suma de arraigo laboral, social y familiar) es del 1,65\% sobre las 747.685 solicitudes presentadas en ese período y del 1,54\% del total de las 473.161 autorizaciones concedidas.

El arraigo laboral presenta un perfil masculino -un $62 \%$ del total de autorizaciones concedidas-, frente a un 38\% de autorizaciones que 
han obtenido mujeres. Las principales nacionalidades más representativas de esta figura son Bolivia con 1214 autorizaciones concedidas, seguidas de Marruecos con 880; Paraguay con 693; Argentina con 380 y Brasil con 385 autorizaciones concedidas, lo que viene a demostrar que los países que la prevalencia del perfil socioestructural es de América Latina, posiblemente debido a facilidad de comunicación porque utilizan el mismo lenguaje, los países tienen un Índice de Desarrollo Humano muy inferior a España y porque estos países no necesitan visados uniformes de corta duración para permanecer en España menos de 90 días -excepción hecha a Bolivia pues desde 1 de abril de 2007 la Unión Europea incluyó a este país entre los que necesitan visado de corta duración-. Marruecos destaca por la proximidad con España y porque determinadas actividades como la Agrícola, la Construcción, suelen emplear a personas de esta nacionalidad.

Para finalizar, un punto de inflexión en este tipo de autorizaciones está sostenido por las dificultades añadidas a las sanciones a las que se enfrenta el empresario, por lo que pudieran soslayarse con el acuerdo verbal con el trabajador inmigrante extranjero y la futura promesa de apoyar la obtención de documentación legal bajo otra modalidad de arraigo, el arraigo social, más barato y más asequible de obtener, sin necesidad de denuncias ni sanciones de por medio.

\section{VI.2 El arraigo social (sociolaboral)}

De los tres tipos de arraigo, el arraigo por excelencia es el que se suele ser conocido como arraigo social, aunque por su naturaleza y características enfoca más las soluciones al no derecho que se hace derecho desde las perspectivas social y laboral, puesto que (demostrar arraigo y contar con contrato de trabajo) entroncan con los matices que vamos a detallar. El arraigo social es el vórtice de las autorizaciones de residencia temporal por circunstancias excepcionales y, como no decirlo, el más dinamizador por la repercusión en cuanto a la gestión completa de los procesos se refiere.

En principio, desde 2006, tiempo en que comienza a generalizarse la gestión del número de solicitudes en todas las Oficinas de Extranjería en España, la confluencia de la irregularidad estructural o sobrevenida desemboca en esta figura de arraigo. Así, por antonomasia, se construyen soluciones legales no solo a quiénes realmente son «capaces» de reunir los requisitos para su otorgamiento -para conseguir una autorización de permanencia legal por esta vía-, sino que desgraciadamente su uso ha recibido un perturbador número de solicitudes 
que no guardan relación con una auténtica integración -perspectiva estática-, sino que se fabrican soluciones a la carta, realizando empadronamientos ficticos en función de la facilidad de obtenerlos; creando empresas ficticias; contrataciones irregulares o ilegales; informes de arraigo sin acreditar ese concepto e incluso falsificando documentación o, más grave aún, incluso la identidad misma.

Es la segunda parte de una entrada irregular; de una entrada ilegal; del apéndice de quienes obteniendo visado de estancia, no regresan a su país de origen (todos, elementos de la irregularidad estructural) o de quienes no pueden obtener la renovación de las autorizaciones de residencia o de residencia y trabajo que venían disfrutando -temporal o de larga duración-.

$\mathrm{Y}$ en su ya dilatada pervivencia, podemos considerar que ha tenido dos etapas: la primera, entre 2006 hasta el 29-06-2011, con el Real Decreto 2393/2004 de 30 de diciembre y la segunda comprende desde el 30-06-2011, fecha de entrada en vigor del Real Decreto 557/2011, de 20 de abril, hasta ahora. Ciertamente entre una u otra etapa, en este tipo de arraigo, a partir de 30-06-2011, la diferencia estaba en la posibilidad de admitir más de un contrato de trabajo en determinados sectores de actividad y con unas concretas condiciones ${ }^{22}$. Pero es a partir de 2011, cuando se produce un descenso paulatino, año tras año, del número de solicitudes y de concesiones.

Entre 2006 y 2014 se solicitaron 687.160 autorizaciones de arraigo social, de las que se concedieron el 62,5\% (429.671 para ser más exactos), según datos facilitados por la Secretaría de Estado de Inmigración y Emigración.

El perfil socioestructural del arraigo social, sigue teniendo como referente ${ }^{23}$ a países de América Latina (Bolivia, con 80776 solicitudes; Paraguay, con 36.369 y Honduras con 12.523), seguido de Marruecos (con 60.041 solicitudes) y Senegal con 12.748. Así hasta un total de 122 países, lo que da una idea de la variedad de nacionalidades representadas.

Los datos y cifras vienen a establecer la imagen estática de los procesos tendentes a obtener la autorización de residencia temporal por esta vía de arraigo, pero en su concepción el arraigo social presenta otras connotaciones:

22 Véase el artículo 124.2.b) del Real Decreto 557/2011, de 20 de abril.

${ }^{23}$ Las cifras se refieren a solicitudes concedidas, puesto que ya hemos mencionado que suponen el $62,5 \%$ del total de solicitudes presentadas y admitidas por las distintas Oficinas de Extranjería. 
I. Para cumplir con el primer requisito (permanencia continuada en España de un mínimo de tres años), los elementos que construyen el proceso de irregularidad, vienen sustentados por:

- Irregularidad estructural.

a) Entrada a España vía marítima o terrestre (resulta menos frecuente la entrada por vía aérea), por puestos fronterizos no habilitados.

b) Entrada a España vía terrestre por puestos fronterizos interiores de la Unión Europea (caso de la frontera con Francia); o bien, por puestos fronterizos exteriores (caso de Ceuta y Melilla) y que no es detectada su presencia en frontera.

c) Entrada en España provistos de visados de estancia de corta duración, pero que incumplen la obligación de volver a los países de origen, antes de que venza el plazo de expiración.

d) Permanencia de tres años continuados sin poder obtener autorización de residencia por arraigo, ubicándose en domicilios «seguros» en una o varias localidades, con demasiada frecuencia viviendo en condiciones muchas veces infrahumanas. El empadronamiento se produce con demasiada frecuencia, de manera fraudulenta, donde por un lado, el arrendador suele ser persona que no tiene nacionalidad española y que, a su vez, actúa como arrendatario y alquila una habitación de la vivienda -piso o casa- a cambio de un precio. Así se acredita la necesidad de poder obtener un informe de arraigo.

e) Imposibilidad de ejecutar salida obligatoria o expulsión del territorio nacional, porque el inmigrante extranjero ostenta una nacionalidad con la que España no tiene suscrito convenio de retorno.

- Irregularidad sobrevenida.

Podríamos considerar que las causas de esta situación se sientan sobre la imposibilidad legal de mantener la permanencia legal que tenía concedida una persona que no tiene la nacionalidad española.

Así las cosas, la residencia temporal que, en situación normal, tiene una residencia inicial y dos renovaciones - de dos años cada unahasta conseguir el Estatuto de residente de larga duración, presenta los siguientes tipos más comunes de irregularidad sobrevenida:

a) Imposibilidad de renovar la residencia temporal que tenía concedida (inicial; por circunstancias excepcionales; con trabajo; 
con excepción a la autorización de trabajo; etc.), principalmente porque no se reúnen los requisitos (falta de medios económicos; si además lleva aparejada autorización de trabajo, porque no se acrediten suficientes cotizaciones en un período determinado).

b) Extinción de la residencia temporal por las causas legales establecidas (fraude de ley en la forma de reunir los requisitos o en el mantenimiento de los mismos; pasaporte o cédula de identidad caducados; ausencia de territorio nacional más de seis meses en un año; comisión de delitos graves penados por el ordenamiento penal español; infracción grave o muy grave que conlleva expulsión del territorio nacional; expulsión firme o prohibición de entrada en territorio Schengen...).

c) Pérdida del Estatuto de residente de larga duración (ausencia continuada de un año en territorio de la Unión Europea; comisión de delito doloso con condena superior a un año; expulsión del territorio nacional por la comisión de determinadas faltas graves o muy graves, expulsión y/o prohibición de entrada en territorio Schengen...).

Es decir, ¿cuánto tiempo de permanencia tiene que justificar una persona para ser reconocida en una determinada localidad? La Ley de Bases de Régimen Local y las normas de desarrollo que regulan el Padrón Municipal, establece que el acto de empadronamiento que gestiona un determinado Ayuntamiento, debe ser inmediato, pero la determinación del arraigo social está, además, sustentado por el informe que los responsables municipales o autonómicos liberen acerca de si existe o no una posición favorable para considerar si un inmigrante extranjero está o no arraigado. Tanto en el caso del acto de empadronamiento, como el de liberar el informe de arraigo, resulta un tema que necesita de soluciones plausibles adecuadas a la realidad social y, dotadas de homologados procedimientos y de homogéneas actuaciones administrativas. Estos dos factores carentes de elementos de gestión común, también son constitutivos de errores sistemáticos que desembocan en ilícitos administrativos y/o penales.

Para sostener una permanencia continuada de dos o tres años, según que se encuadre en el arraigo laboral o en el arraigo social, es requisito imprescindible demostrar la presencia en alguna localidad española, surgiendo con ello múltiples controversias sobre la interpretación de que el arraigo tiene un fuerte componente local y no regional o nacional. 
Otro punto fundamental de este análisis, pero concretado en el arraigo social, lo constituye el contrato de trabajo estable entendiendo por tal el suscrito entre empleador y trabajador inmigrante extranjero, con duración mínima de un año. Compromiso que, con la situación coyuntural del mercado de trabajo en España, resulta de verdadero hándicap por su escaso cumplimiento, con lo cual, la obligación de flexibilizar su aplicación, es un hecho incuestionable. Pero este elemento principal, en realidad se sitúa en el lado contrario de la regulación del mercado laboral en España, pues si existe uno de los índices de desempleo más altos de Europa, no parece fiable que el contrato estable en la mayoría de las ocasiones, se presente como una solución al arraigo social y en el trabajo no cualificado sobre el que se sostiene la mayoría del arraigo social, indudablemente no contribuye a disminuir uno de los problemas principales en España: el paro.

\section{VI.3 El arraigo familiar}

Por último, el arraigo familiar es la tercera vía del concepto legal de arraigo. Pueden acogerse dos grupos de inmigrantes extranjeros. El primero, los que tengan hijos a los que se les haya reconocido la nacionalidad española. El segundo grupo está formado por los que puedan acreditar haber sido hijos de padre o madre originariamente españoles. El primero, de más reciente regulación, tuvo su andadura a partir del Real Decreto 557/2011, y el segundo se gestionaba ya desde el derogado y antecesor Real Decreto 2393/2004.

El arraigo familiar supone el 6,44\% del total de autorizaciones solicitadas (ya pusimos que la suma de laboral, social y familiar ascendía a 747.685 solicitudes) y el 7,6\% del total de autorizaciones concedidas sobre el total de 473.161. La representatividad en este tipo de arraigo es escasa, pero desde la perspectiva cualitativa presenta disyuntivas muy apreciables. El perfil socioestructural del arraigo familiar tiene dos etapas claramente diferenciadas.

Por un lado, la primera etapa se caracteriza porque únicamente accedían a este tipo de arraigo quiénes acreditaran haber sido hijos de padre o madre originariamente españoles. Comprende el período desde 2006 hasta 2010 y las principales nacionalidades tenían un componente magrebí (Argelia, Marruecos, Mauritania y el Sahara Occidental) que suponía un 63\% sobre las 2943 concedidas en esa etapa, oscilando en ese período, por el número de solicitudes conce- 
didas, de América Latina (Argentina, Cuba, Venezuela, Brasil), que únicamente supone el 19\% de las concedidas.

La segunda etapa que comienza desde 2011 hasta ahora, se caracteriza por una ampliación del acceso a este tipo de arraigo, de los padres o madres de un menor de nacionalidad española, lo que vino a representar un importante incremento del número de solicitudes de ciudadanos procedentes de América Latina (Bolivia, Paraguay, Colombia; Ecuador, Brasil) y muy por detrás, quedan los países del Magreb (principalmente Marruecos y Argelia) ${ }^{24}$.

El arraigo familiar no necesita acreditar una permanencia continuada en España; no necesita aspirar a un puesto de trabajo y no necesita acreditar arraigo, bajo los parámetros del arraigo laboral y del arraigo social, lo que viene a facilitar con escasas garantías, el acceso a la residencia temporal por circunstancias excepcionales.

Pero para pasar del mundo de la teoría, al mundo de la experiencia, se precisa -como mínimo- reflexionar sobre los errores sistemáticos que se vienen produciendo y en ese sentido, el arraigo familiar, en el grupo de padres y madres de menores españoles, tiene un alto componente de irregularidad sobrevenida. El proceso acoge principalmente a países de América Latina, que suelen estar amparados por los Tratados de doble nacionalidad que España. Y desde la perspectiva de la irregularidad estructural, las víctimas de trata y las víctimas de violencia de género y del entorno familiar, suelen acceder por esta vía al derecho desde el no derecho.

Por lo que respecta al segundo grupo; esto es, tener la condición de hijos de padre o madre originariamente españoles, la cuestión se torna, por un lado positiva, por cuanto que personas cuyos padres españoles tuvieron que renunciar por distintos motivos, a la nacionalidad española, se pueden acoger a esta solución plausible y regresar a España, pudiendo residir y trabajar desde el momento de la concesión de la solicitud de residencia temporal por esta vía.

Pero en la vertiente negativa, la situación contiene demasiados errores sistemáticos, principalmente cuando se trata de nacionales nacidos en el Sahara Español, durante la etapa en que España gobernaba las provincias de Saguia el Hamra y Río de Oro hasta 1976, en que se materializó el abandono de España del territorio. El hecho en

${ }^{24}$ En el período 2011-2014 se concedieron un total de 31.503 solicitudes de arraigo familiar. Los países que describimos de América Latina suman 18.183 aprobadas, que supone el 58\% del total, frente a Marruecos y Argelia que apenas llegan al 10\% de las concedidas (3.077). Fuente: Secretaría General de Inmigración y Emigración y elaboración propia. 
sí, desde esa época, ha generado interpretaciones acerca de la nacionalidad española de los saharauis y esta indeterminación jurídicoadministrativa, viene a promover la irregularidad estructural, principalmente, y, como efecto secundario, la irregularidad sobrevenida, debido a la indeterminación sobre la validez de los documentos que permitirían acceder a la residencia temporal por arraigo familiar. A toda esta situación carente de procesos válidos y fiables, se une la falta de acuerdos para poder determinar soluciones entre los Ministerios españoles con competencia en su gestión; principalmente el Ministerio de Empleo y Seguridad Social; el Ministerio de Asuntos Exteriores y el Ministerio del Interior.

\section{CONCLUSIONES}

La regulación permanente en España necesita una reflexión profunda en torno a su viabilidad, pues lo que inicialmente se construía como una figura que preveía regular la presencia de migración en situación irregular, se ha consolidado como un mecanismo poco fiable, puesto que los requisitos se simulan con una generalidad, que afecta a la gestión de los procesos de arraigo. Mantener el arraigo en su concepción primaria, bajo una pléyade de requisitos agrupados en la justificación de la permanencia en territorio español un mínimo de dos o tres años, para dar curso a la solicitud de arraigo laboral o sociolaboral, pudiera ser contrario a los principios y valores superiores de nuestro Ordenamiento Jurídico.

La presencia ausente se vislumbra y se percibe notoriamente, pero la regulación del no derecho que se hace derecho, queda al margen de esa realidad, pues si bien ha disminuido gradualmente la irregularidad estructural, el mecanismo se retroalimenta transformándose en irregularidad sobrevenida y ésta, a su vez, vuelve a los procesos para mantener el mismo status residente temporal. Una residencia que nace con incertidumbre y se ampara en la incertidumbre hasta llegar a la residencia de larga duración. Y como hemos analizado, lo excepcional se torna general.

Para finalizar, la co-inclusión recíproca se percibe como una aspiración, si cabe, más allá del proceso de integración que igualmente, está cargado de formas estereotipadas que se circunscriben a los formalismos administrativos, lejos de soluciones a la dignidad que nuestra Constitución hace valedora con la Declaración Universal de Derechos Humanos y ésta debe conectar con la regulación de las 
migraciones, asistida por la normativa de la Unión Europea, en aras de equilibrar la permanencia legal con la migración irregular.

\section{A MODO DE DISCUSIÓN}

A lo largo de prácticamente estos 10 años que ha comprendido el ámbito reflexivo-descriptivo de del arraigo nos permite emplazar a las siguientes reflexiones, más acentuadas si cabe, que las síntesis generalistas de las conclusiones, pues el arraigo se deviene como una solución menos agresiva a la regulación de las migraciones irregulares, pero a la pertinaz llegada de personas de otras nacionalidades, permiten proliferarse posturas pusilánimes que se sientan sobre las siguientes inquietudes:

¿El arraigo se ha consolidado como la promoción de una parte importante de las migraciones irregulares en España? Y, dependiendo de las áreas socioestructurales ¿representa una forma de regulación legal hacia Europa?

El arraigo se torna continuista del fracaso de las políticas activas de empleo que afectan a los nichos laborales ocupados por personas de terceros países. ¿Empleo o sobreexplotación laboral migrante? ¿Por qué se mantiene el pulso del arraigo social con contrato de trabajo que se contradice con la cifra de parados en nuestro país?

¿Por qué no se analizan soluciones plausibles al arraigo familiar, hijos de padre o madre originariamente españoles, sin que sea necesario dejar al albur de la interpretación jurídica en base a soluciones judiciales contradictorias?

¿Necesitamos en España mayor cualificación y preparación para afrontar la gestión de las políticas migratorias desde las Instituciones?

El modelo institucional de gestión de los procesos migratorios se sostiene por los Ministerios de Empleo y Seguridad Social; de Interior; de Hacienda y Administraciones Públicas y de Asuntos Exteriores ¿Podemos diseñar modelos más eficientes de cara a afrontar la gestión de las migraciones en España?

Un estudio más pormenorizado nos permitirá inferir preguntas de investigación, capacidades y respuestas a esta figura por la que se accede desde el no derecho que se hace derecho. 


\section{REFERENCIAS}

ARANGO, J. (2005). Dificultades y Dilemas de las Políticas de Inmigración. Arbor CLXXXI. Mayo-junio (17-25). Recuperado el 12-05-2015 de la web http://arbor.revistas.csic.es.

BAUMANN, G. (2001). El enigma multicultural. Barcelona: Paidós.

DE LUCAS, J. (2011). Inmigrantes. Del estado de excepción al Estado de derecho. Oñati Socio-Legal Series, V. 1, n. ${ }^{\circ} 3$.

- (2014). Los movimientos de derechos por los sin derecho: la solidaridad con inmigrantes y refugiados. Revista Andaluza de Antropología. n. 6. (78-98).

DASSETTO, F. (2004). Más allá de lo intercultural: los retos de la coinclusión. Revista Cidob D`Afers Internacionals 66-67. Recuperado el 18-12-2013 de la web http://www.cidob.org.

GOIG, JM. (2008). Inmigración y Derechos Fundamentales. Madrid: Universitas Internacional, S.L.

IZQUIERDO, A. y LEÓN-ALFONSO, S. (2008). La inmigración hacia dentro: argumentos sobre la necesidad de la coordinación de las políticas de inmigración en un Estado multinivel. Revista Política y Sociedad. Vol. 45. 1: (11-39).

LLÍES, M. (2009). La política de la Comunidad Europea sobre inmigración irregular: medidas para combatir la inmigración irregular en todas sus fases. Documento de Trabajo 38/2009. Real Instituto Elcano. Recuperado el 15-04-2014 de la web http://realinstitutoelcano.org

SARTORI, G. (2003). La sociedad miltiétnica. Madrid: Taurus. 